\title{
Predictors of success for mandibular repositioning appliance in obstructive sleep apnea syndrome
}

Thays Crosara Abrahão CUNHA ${ }^{(a)}$ Thais de Moura GUIMARÃES(b) Teresa Cristina Barros SCHULTZ(b) Fernanda Ribeiro de ALMEIDA(c) Thulio Marquez CUNHA ${ }^{\text {(d) }}$ Paulo Cezar SIMAMOTO JUNIOR(a) Lia Rita Azeredo BITTENCOURT ${ }^{(b)}$

\footnotetext{
(a) Universidade Federal de Uberlândia - UFU, School of Odontology, Department of Oclusão, Prótese Fixa e Materiais Odontológicos, Uberlândia, MG, Brazil.

(b) Universidade Federal de São Paulo - Unifesp, School of Medicine, Department of Psicobiologia, São Paulo, SP, Brazil.

(c) University of British Columbia, Department of Oral Health, Vancouver, Canada.

(d) Universidade Federal de Uberlândia - UFU, School of Medicine, Department of Pneumology, Uberlândia, MG, Brazil.
}

Declaration of Interest: The authors certify that they have no commercial or associative interest that represents a conflict of interest in connection with the manuscript.

\section{Corresponding Author:}

Thays Crosara Abrahão Cunha

E-mail: thayscrosara@gmail.com

hHtps://doi.org/10.1590/1807-3107BOR-2017.vol31.0037

Submitted: Sep 03, 2016

Accepted for publication: Mar 21, 2017

Last revision: Apr 07, 2017
Abstract: The characteristics of non-obese patients with mild to moderate Obstructive Sleep Apnea Syndrome (OSAS) who will present with a good response to Mandibular Repositioning Appliance (MRA) treatment have not yet been well established in the literature. The aim of this study is to assess whether polysomnographic (PSG), demographic, anthropometric, cephalometric, and otorhinolaryngological parameters predict MRA success in the treatment of OSAS. Forty (40) males with mild and moderate OSAS were assessed pretreatment and 2-months post-treatment after wearing an MRA. Demographic, anthropometric, otorhinolaryngological (ENT), cephalometric, and polysomnographic parameters, including continuous positive airway pressure (CPAP) titrated pressure, dental models, Epworth Sleepiness Scale, quality of life (Short Form SF-36), and mood state (Profile of Mood States - POMS), were assessed. The responders exhibited fewer oropharyngeal alterations, increased upper pharyngeal space, reduced lower airway space, and increased mandibular intercanine width, and they had milder disease. Nevertheless, no predictive factors of MRA success could be found. MRA was more successful among men with a more pervious airway, a larger interdental width and milder OSAS. However, a combined [1] functional and structural assessment is needed to successfully predict the [2] effectiveness of MRA treatment of OSA.

Keywords: Polysomnography; Orthodontic Appliances;

Otorhinolaryngologic Diseases; Cephalometry; Continuous Positive Airway Pressure.

\section{Introduction}

Obstructive sleep apnea syndrome (OSAS) is a highly prevalent sleep-related respiratory disorder characterized by a total or partial obstruction of the upper airways concomitant with respiratory effort during sleep, causing intermittent hypoxemia and sleep fragmentation. ${ }^{1}$

In the first studies, the prevalence of OSAS - defined by an apnea-hypopnea index (AHI) greater than five events per hour - was estimated to be between $6.5 \%$ and $9 \%$ in women and between $17 \%$ and $31 \%$ in men. ${ }^{2}$ However, this prevalence has since been revised to be approximately $34 \%$ in men aged $30-70$ years and $17 \%$ in women aged $30-70$ years. ${ }^{3}$ In a study from Brazil with 1042 participants aged 20-80 years, 
the researchers reported a higher prevalence (AHI > 5) of $46.6 \%$ in men and $30.5 \%$ in women. ${ }^{4}$ A population-based study in Switzerland reported that the prevalence of moderate-to-severe OSAS (AHI $\geq 15$ ) was $23.4 \%$ in women and $49.7 \%$ in men. ${ }^{5}$ Obesity, male gender, age and craniofacial alterations are the principal risk factors. In addition to the high prevalence, this disorder has health consequences such as cardiovascular and metabolic diseases, automobilist crash risk and higher mortality rate. ${ }^{6}$

Continuous Positive Airway Pressure (CPAP) is the gold standard for OSAS treatment. However, tolerance and treatment adherence are low, which reduces the effectiveness. The use of a Mandibular Repositioning Appliance (MRA) is indicated in patients with a primary snore, mild OSAS or who are CPAP intolerant. ${ }^{7}$ Despite the low MRA rate of success of $48 \%,{ }^{8}$ important health outcomes were similar after 1 month of optimal MRA and CPAP treatment in patients with moderate severe OSAS. The results may be explained by the greater efficacy of CPAP being offset by inferior compliance relative to MRA, resulting in similar effectiveness. ${ }^{9}$

However, the inability to predict which patients will respond well to the treatment limits the clinical use of an MRA. ${ }^{10}$ The construction of a custom-made device for each patient and a titration period for the mandible to adapt demands time and money. ${ }^{11}$ Factors such as a younger age, lower body mass index (BMI), smaller neck circumference, female gender, lower AHI (apnea-hypopnea index), increased amount of mandibular advancement, and the need for CPAP pressure lower than $10.5 \mathrm{~cm} \mathrm{H}_{2} \mathrm{O}$ were postulated as predictors of short-term success. ${ }^{11,12,13,14}$ Studies have evaluated cephalometric parameters, spirometer results, drug-induced sleep endoscopy, remotely controlled mandibular positioners, multisensory catheter parameters and dental model analysis to predict the success of OSAS treatment using an MRA. $14,15,16,17,18,19,20,21,22,23$. In spite of obtaining good results, studies that evaluate the remotely controlled mandibular positioner and drug-induced sleep endoscopy are very difficult to execute. ${ }^{8}$

To predict the success of the MRA, it is fundamental that Polysomnography (PSG) be used with accurate criteria sucess. The predictor must be simple, not invasive and easily accessible. ${ }^{8}$ Therefore, the aim of the present study was to assess in a prospective study whether demographic, anthropometric, Ear, Nose and Throat evaluation (ENT), cephalometric, and PSG factors, including CPAP titration pressure and an analysis of dental models, might predict the success of MRA in the treatment of OSAS in non-obese, non-severe, male patients.

\section{Methodology}

Men aged 25 to 65 years old with a BMI of $\leq 30 \mathrm{~kg} / \mathrm{m}^{2}$ and $\mathrm{OSAS}^{24}$ were selected in the outpatient sleep clinic at Unifesp, Brazil. The exclusion criteria were decompensated clinical morbidities, sleep disorders, alcoholism, the use of sleep inducers, and sleep deprivation. Other criteria included intolerance to the use of CPAP on the titration night, previous treatment for OSAS, dental alterations hindering the use of an MRA such as less than 10 teeth per dental arch, periodontal and dental problems, severe temporomandibular disorders, and a maximum mandibular protrusion of less than $4 \mathrm{~mm}$. The protocol was approved by the research ethics committee of the Unifesp (0352/09) and was registered at ClinicalTrials.gov (NCT01336556). The participants signed informed consent forms. The study protocol is presented in Figure 1.

Full night complete PSG was performed in a lab (EMBLA® S7000, Embla Systems, Inc., Broomfield, USA). Sleep staging was performed according to the Restchafen and Kales' criteria, ${ }^{25}$ and events were scored according to the American Academy of Sleep Medicine criteria (AASM).$^{26}$ OSAS severity was classified according to AASM criteria. ${ }^{27} \mathrm{CPAP}$ devices (REMstar ${ }^{\circledR}$ Plus; Respironics Inc., Murrysville, PA) with a nasal mask were used. The CPAP titration was manually performed per guidelines. ${ }^{28}$ The analyzed anthropometric measures were BMI and neck circumference. The ENT assessment was performed according to Zonato et al. ${ }^{29}$ (Table 1). Lateral tele radiographs were acquired with a Vatech - PaX 400 device, and Radioed Studio software was used to generate the cephalometric analysis (the mandibular and maxillary position in relation to the cranium, the length and flexion of the cranium base, the length of the mandibular and maxilla, the hiode position, 


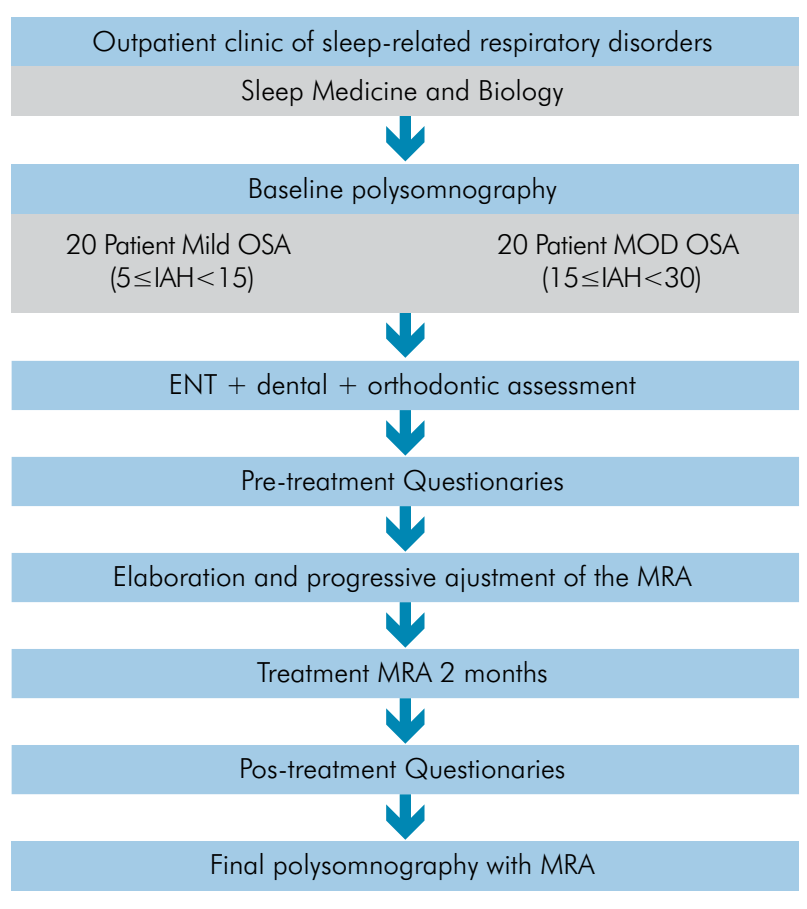

Figure 1. Study protocol.

the superior and medium pharyngeal space and the length and width of the soft palate) (Figure 2). Dental models were used for linear measurements of the oral cavity size. The following measurements were performed using a dry-tip compass: intercanine width, interpremolar width, intermolar width, maxillary and mandibular lengths, palate height and mouth floor depth. All the patients responded to questionnaires before and after treatment: the Epworth Sleepiness Scale (ESS), ${ }^{30}$ the Short Form Health Survey (SF-36) ${ }^{31}$ and the Profile of Mood State (POMS). ${ }^{32}$

The Brazilian Dental Appliance (BRD) MRA, individualized, in acrylic, with two plaques allowing a progressive advance, was used. ${ }^{33}$ The initial position was set as $50 \%$ of the maximum protrusion followed by $1 \mathrm{~mm}$ advancements every 7 days until the maximum comfortable protrusion or the maximum protrusion recorded at the initial assessment was achieved. The individuals who achieved an AHI with an MRA of $<5$ associated with a reduction of at least $50 \%$ of the baseline AHI were considered responders. ${ }^{20,34}$

Statistical analyses were performed with SPSS version 18 software. The normality of data was assessed with the Kolmogorov-Smirnov test. To compare the variables before and after treatment, a paired Student's
Table 1. Evaluation ENT.

\begin{tabular}{|c|c|c|}
\hline $\begin{array}{l}\text { Craniofacial } \\
\text { alteration }\end{array}$ & $\begin{array}{l}2 \text { of the } \\
\text { following }\end{array}$ & $\begin{array}{l}\text { Angle class II malocclusion } \\
\text { retrognathic facial profile } \\
\text { Ogival palate }\end{array}$ \\
\hline $\begin{array}{l}\text { Unfavorable } \\
\text { nose }\end{array}$ & $\begin{array}{l}1 \text { of the } \\
\text { following }\end{array}$ & $\begin{array}{l}\text { Septum deviation grade II or III } \\
\text { Turbinate hypertrophy + rhinitis or } \\
\text { obstruction of complaint nose } \\
\text { Septum deviation grade I + rhinitis } \\
\text { or obstruction of complaint nose }\end{array}$ \\
\hline $\begin{array}{l}\text { Unfavorable } \\
\text { oropharynx }\end{array}$ & $\begin{array}{l}3 \text { of the } \\
\text { following }\end{array}$ & $\begin{array}{c}\text { Palate WeB } \\
\text { More posterior or tick palate } \\
\text { Long or thick uvula } \\
\text { Medial pillars } \\
\text { Tonsils grade III or IV }\end{array}$ \\
\hline $\begin{array}{l}\text { Unfavorable } \\
\text { mallampati }\end{array}$ & & Class III or IV \\
\hline
\end{tabular}

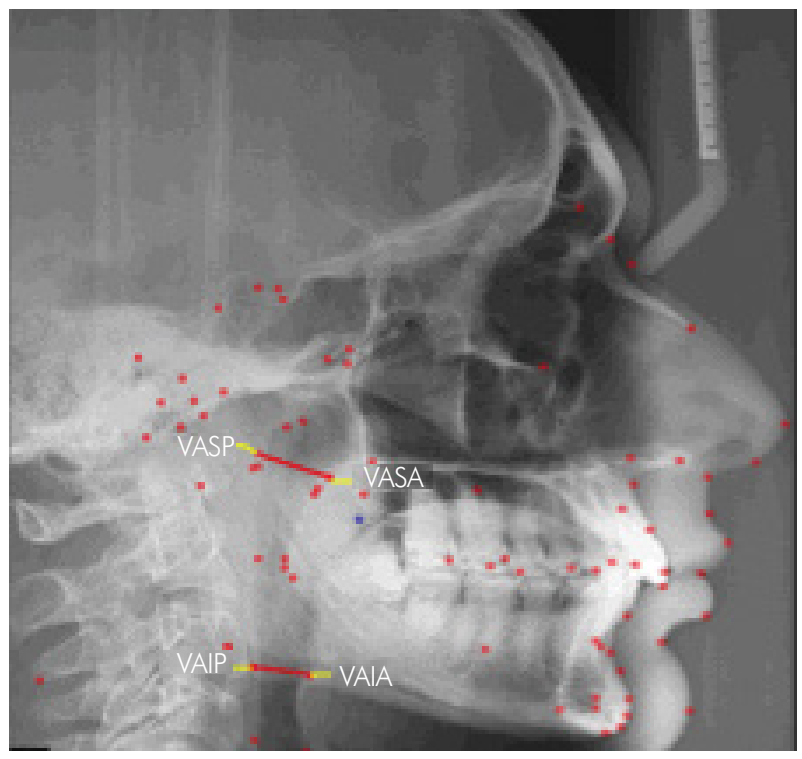

Figure 2. Schematic lateral cephalogram illustrating the upper pharyngeal space (VASP-VASA) and lower airway space (VAIP-VAIA).

t-test or a Wilcoxon test was used. The comparison of variables between the responders and non-responders before and after treatment was performed using the chi-square test, a Mann-Whitney test or Student's t-test. Receiver operating characteristic curves (ROCs) were 
elaborated to establish cut-off points predictive of success for the continuous variables. Logistic regression was performed using new variables categorized by means of the ROC curve to identify the variables that most influenced success. The $\Delta$ percentage of the preand post-treatment AHIs was also calculated and used as a dependent variable in the linear regression analysis. In all analyses, the level of significance was established as 0.05 , i.e., $\mathrm{p} \leq 0.05$.

\section{Results}

Forty-three (43) patients were selected, among which one (1) was not able to use the MRA and two (2) did not return for the final PSG.
Participants' initial characteristics and responses to treatment are presented in Table 2 and 3. The final sample comprised 40 men, 20 with mild OSAS and 20 with moderate OSAS, $65 \%$ of whom responded to treatment $(p=0.05)$. The objective assessment of sleep by means of the PSG shows that MRA treatment induced a significant reduction in the AHI $(p=0.000)$, and $85 \%$ of the participants exhibited a reduction of at least $50 \%$ of the baseline AHI.

The individuals with mild OSAS exhibited a greater response to treatment compared to the individuals with moderate OSAS ( $p=0.05)$, although the baseline AHI and the CPAP titration pressure did not differ ( $p=0.314$ and $p=0.091$, respectively). An analysis of the changes in the PSG parameters in the responders

Table 2. All patients $(n=40)$ - Pre- and post-treatment data.

\begin{tabular}{|c|c|c|}
\hline \multirow{2}{*}{ Variables } & Pre-treatment & Post-treatment \\
\hline & (95\%Cl/SE) & (95\% Cl/SE) \\
\hline $\mathrm{BMI}\left(\mathrm{kg} / \mathrm{m}^{2}\right)$ & $(24.0-27.8) / 0.9$ & $(24.3-28.0) / 0.9$ \\
\hline $\mathrm{AHI}$ (events/hour) & $(12.0-18.1) / 1.5$ & $(2.1-8.1) / 1.4^{*}$ \\
\hline Sleep onset latency (min) & $(5.0-10.5) / 1.3$ & $(4.3-20.7) / 3.9$ \\
\hline Total sleep time (min) & (350.2-405.3) / 13.2 & (339.1-390.9) / 12.3* \\
\hline Sleep efficiency (\%) & $(78.5-88.6) / 2.4$ & $(79.4-89.6) / 2.4^{*}$ \\
\hline Arousal index & $(15.0-21.9) / 1.6$ & $(9.4-14.7) / 1.3^{*}$ \\
\hline Baseline $\mathrm{SaO}_{2}$ & $(94.8-96) / 0.3$ & $(95.0-96.2) / 0.3$ \\
\hline Mean $\mathrm{SaO}_{2}$ & $(94.2-95.5) / 0.3$ & $(94.4-95.7) / 0.3$ \\
\hline $\mathrm{Min} \mathrm{SaO}_{2}$ & $(86.8-89.4) / 0.62$ & $(88.7-91.5) / 0.7^{*}$ \\
\hline Epworth & $(9.8-15.1) / 1.25$ & $(5.1-9.9) / 1.1$ \\
\hline \multicolumn{3}{|l|}{ POMS } \\
\hline Tension & $(7.4-12.6) / 1.2$ & $(5.2-10.9) / 1.4$ \\
\hline Depression & $(4.2-11.1) / 1.6$ & $(3.7-11.3) / 1.8$ \\
\hline Anger & $(5.2-12.7) / 1.8$ & $(3.8-11.4) / 1.8$ \\
\hline Fatigue & $(8.0-12.6) / 1.1$ & $(4.0-9.6) / 1.3$ \\
\hline Vigor & $(13.8-18.0) / 1.0$ & $(14.2-20.1) / 1.4$ \\
\hline Confusion & $(5.0-8.4) / 0.8$ & $(1.4-6.1) / 1.3$ \\
\hline Total score & $(15.4-40.1) / 5.9$ & $(1.3-30.2) / 6.9$ \\
\hline \multicolumn{3}{|l|}{ SF-36 } \\
\hline Physical functioning & $(66.8-89.0) / 5.3$ & $(84.3-97.3) / 3.1$ \\
\hline Limitation physical features & $(51.3-82.1) / 7.4$ & $(73.4-95.0) / 5.1$ \\
\hline Pain & $(59.1-78.9) / 4.7$ & $(68.4-90.4) / 5.2$ \\
\hline General health & $(63.8-9.8) / 3.8$ & $(71.5-86.2) / 3.8$ \\
\hline Vitality & $(46.2-63.8) / 4.2$ & $(57.7-75.0) / 4.1$ \\
\hline General features & $(71.0-90.9) / 4.8$ & $(70.6-91.2) / 4.9$ \\
\hline Limitation emotional features & $(63.8-94.9) / 7.4$ & $(56.3-91.1) / 4.2$ \\
\hline Mental health & $(57.7-74.9) / 4.1$ & $(64.1-81.6) / 4.2$ \\
\hline
\end{tabular}

BMI: body mass index; AHI: apnea/hypopnea index. Data presented as confidence intervals (Cls) and standard errors of the mean (SEs) paired Student's t-test and the Wilcoxon test; ${ }^{*} p>0.05$ 
Table 3. Responders and non-responders - Pre- and post-treatment data.

\begin{tabular}{|c|c|c|c|c|}
\hline \multirow{3}{*}{ Variables } & \multicolumn{2}{|c|}{ Responders $(n=26)$} & \multicolumn{2}{|c|}{ Non-responders $(n=14)$} \\
\hline & Pre-treatment & Post-treatment & Pre-treatment & Post-treatment \\
\hline & (95\%Cl/SE) & (95\%Cl/SE) & (95\%Cl/SE) & (95\%Cl/SE) \\
\hline BMI $\left(\mathrm{kg} / \mathrm{m}^{2}\right)$ & $(24.0-27.8) / 0.9$ & $(24.3-28.0) / 0.9$ & & \\
\hline $\mathrm{AHI}$ (events/hour) & $(9.9-17.2) / 1.7$ & $(1.7-3.1) / 0.3^{*}$ & $(11.4-23.8) / 2.6$ & $(2.6-17.3) / 3.0^{*}$ \\
\hline Sleep onset latency (min) & $(3.5-8.6) / 1.2$ & $(2.4-20.4) / 4.1$ & $(4.1-16.9) / 2.7$ & $(-6.0-35.0) / 8.4$ \\
\hline Total sleep time (min) & $(332.4-411.6) / 18.2$ & $(346.2-402.8) / 12.8^{*}$ & $(341.7-432.5) / 19.2$ & $(286.5-411.1) / 25.5$ \\
\hline Sleep efficiency (\%) & $(75.5-89.6) / 3.2$ & $(79.1-90.1) / 2.5^{*}$ & $(76.4-94.1)-3.8$ & $(71.2-97.2) / 5.3$ \\
\hline Arousal index & $(13.2-24.0) / 2.5$ & $(8.7-16.1) / 1.7^{*}$ & $(14.3-22.1) / 1.6$ & $(6.6-6.6) / 2.0$ \\
\hline Baseline $\mathrm{SaO}_{2}$ & $(94.5-95.8) / 0.3$ & $(95.0-96.1) / 0.3$ & $(94.7-97.1) / 0.5$ & $(93.9-97.3) / 0.7$ \\
\hline Mean $\mathrm{SaO}_{2}$ & $(93.9-95.3) / 0.3$ & $(94.5-95.7) / 0.3$ & $(93.6-96.8) / 0.7$ & $(93.2-96.6) / 0.7$ \\
\hline $\mathrm{Min} \mathrm{SaO}_{2}$ & $(86.1-89.2) / 0.7$ & $(89.8-92.0) / 0.5^{*}$ & $(86.0-91.5) / 1.2$ & $(85.0-92.4) / 1.5$ \\
\hline Epworth & $(12-17) / 1$ & $(2.6-6.6) / 0.8^{*}$ & $(4.30-14.0) / 2.0$ & $(5.8-12.6) / 1.6^{*}$ \\
\hline \multicolumn{5}{|l|}{ POMS } \\
\hline Tension & $(7.7-14.4) / 1.5$ & $(5.2-13.6) / 1.9^{*}$ & $(3.4-13.3) / 2.1$ & $(2.3-9.2) / 1.4$ \\
\hline Depression & $(4.4-13.2) / 2.0$ & $(3.1-13.9) / 2.4$ & $(-0.9-12.6) / 2.9$ & $(-0.6-12.3) / 2.7$ \\
\hline Anger & $(5.2-12.5) / 1.7$ & $(3.3-14.3) / 2.5$ & $(-0.5-18.7) / 4.1$ & $(-0.4-11.3) / 2.4$ \\
\hline Fatigue & $(7.5-14.5) / 1.6$ & $(2.7-11.1) / 1.9^{*}$ & $(6.0-12.3) / 1.3$ & $(2.5-11.0) / 1.7$ \\
\hline Vigor & (12.6-18.3)/1.3 & $(14.6-21.4) / 1.6$ & $(12.6-20.7) / 1.7$ & $(8.8-22.6) / 2.8$ \\
\hline Confusion & $(4.5-9.5) / 1.2$ & $(0.7-7.5) / 1.6^{*}$ & $(3.5-9.0) / 1.2$ & $(-0.87 .1) / 1.6$ \\
\hline Total Score & $(16.0-46.5) / 7.0$ & $(-1.1-40.6) / 9.5$ & $(-3.7-47.9) / 10.9$ & $(-14.2-32.2) / 9.5$ \\
\hline \multicolumn{5}{|l|}{ SF-36 } \\
\hline Physical functioning & $(61.5-92.4) 7.1$ & $(84.8-100.2) / 3.5$ & $(59.3-99.4) / 8.5$ & $(73.0-102.7) / 6.1$ \\
\hline Limitation physical features & $(50.8-91.5) / 9.3$ & $(69.2-97.4) / 6.4$ & $(23.0-88.8) / 12.4$ & $(63.2-108.3) / 9.2$ \\
\hline Pain & $(52.3-79.2) / 6.2$ & $(65.1-96.2) / 7.0^{*}$ & $(56.4-91.8) / 7.5$ & $(57.3-97.0) / 8.1$ \\
\hline General health & $(65.2-82.7) / 4.0$ & $(72.7-87.0) / 3.2$ & $(49.6-87.1) / 7.9$ & $(57.4-96.9) / 8.1$ \\
\hline Vitality & $(41.2-66.5) / 5.8$ & $(56.7-75.8) / 4.4^{*}$ & $(42.2-71.5) / 6.2$ & $(44.8-88.1) / 8.8$ \\
\hline General features & $(68.4-95.0) / 6.1$ & $(64.2-94.0) / 6.8$ & $(60.4-99.0) / 8.2$ & $(66.6-101.2) / 7.1$ \\
\hline Limitation emotional features & $(65.1-104.1) / 8.9$ & $(41.1-92.2) / 11.6$ & $(39.4-102.2) / 13.3$ & $(61.4-110.0) / 9.9$ \\
\hline Mental health & $(50.2-74.7) / 5.6$ & $(56-78.7) / 5.2$ & $(59.7-85.3) / 5.4$ & $(67.8-96.8) / 5.9$ \\
\hline
\end{tabular}

BMI: body mass index; AHI: apnea/hypopnea index. Data are presented as confidence intervals (Cls) and standard errors of the mean (SEs); Mann-Whitney and Student's t-tests; ${ }^{*} p>0.05$.

and non-responders for the pre- and post-treatment periods showed that although the $\Delta \mathrm{AHI}$ was greater in the responders, the difference was not significant $(p=0.07)$. Conversely, the $\Delta$ of the average saturation was significantly greater in the responders $(p=0.011)$.

The parameters of age, BMI, and neck circumference did not exhibit significant differences between the responders and non-responders. Individuals with pharyngeal alterations exhibited less response to this therapeutic modality $(\mathrm{p}<0.05)$ (Table 4).

When cephalometric variables were analyzed, the responders exhibited a significantly larger upper pharyngeal space $(p=0.032)$ and smaller lower airway space $(p=0.042)$ (Figure 2). The analysis of interdental measures demonstrated that the responders had increased lower intercanine width compared to the non-responders $(\mathrm{p}=0.029)$.
Table 4. ENT parameters for the responders and non-responders.

\begin{tabular}{lcc}
\hline ENT Parameters & $\mathrm{x}^{2}$ & $\mathrm{p}$ \\
\hline Craniofacial alterations & 1.50 & 0.16 \\
Pharyngeal alterations & 3.57 & $0.05^{*}$ \\
Evident nasal alteration & 0.81 & 0.25 \\
Modified Mallampati score & 0.01 & 0.56 \\
\hline
\end{tabular}

Chi square ; ${ }^{*} p>0.05$

The ESS score was similar at baseline but showed a significantly greater improvement in responders when compared to non-responders ( $p=0.05)$. The POMS and SF-36 parameters did not exhibit significant differences between those groups before and after treatment.

ROC curves for the continuous variables that exhibited statistically significant values between 
responders and non-responders were generated. The variables included lower airway space, upper pharyngeal space, and lower intercanine width. Larger area under the curves (AUCs) and significant p-values were found for upper pharyngeal space (AUC $=0.707$ and $\mathrm{p}=0.032)$ and lower pharyngeal space $(\mathrm{AUC}=0.691$ and $p=0.049)$. The intercanine distance showed an AUC of 0,257 . When the proposed literature cut-off value was used, a CPAP of $10,5 \mathrm{~cm} \mathrm{H}_{2} \mathrm{O}$, the AUC was 0.377 .

Univariate and multivariate logistic regression was performed using the selected criterion of success adopted as a dependent variable. However, this analysis did not allow the selection of any variable. Next, we performed a multivariate linear regression analysis using the $\Delta$ percentage of AHI before and after treatment as the dependent variable for all of the variables analyzed. However, we were once again not able to identify any variable that was able to predict the success of OSAS treatment using an MRA.

\section{Discussion}

The present study assessed demographic, anthropometric, and PSG parameters, including CPAP titration pressure, ENT alterations, cephalometric parameters, and dental model analysis as possible predictors of the success of an OSAS treatment using an MRA in a prospective study. In our non-obese population, fewer factors appeared to influence the prediction of treatment outcomes.

Our results show that treatment success in non-obese, non-severe OSA patients with an MRA was greater among patients with milder OSAS, an absence of pharyngeal alterations, increased upper pharyngeal space, reduced lower airway space, increased mandibular intercanine width, and a greater reduction in sleepiness following treatment. However, none of these factors were predictive of the response to the MRA when plotted in a regression an analysis.

The reported efficacy of OSAS treatments using an MRA regarding AHI, arousal index, post-treatment minimum oxygen saturation, excessive daytime sleepiness and quality of life indices was also observed in the present study. ${ }^{35,36}$

Even though studies show that the response to treatment presents an inverted correlation to basal $\mathrm{AHI}^{14}$ and we have observed that patients with mild OSAShad a better response to treatment, significant differences between the responders and non-responders were absent. The observed success rate was $65 \%$ percent, which corroborated with other studies that also dealt with individuals with severe OSAS, suggesting that the success of treatment of OSAS with the use of MRA might not depend on severity and might be more related to the nature of a multi factorial disease. ${ }^{37,38}$

Otsuka et al. ${ }^{39}$ assessed the effect of craniofacial traits on the success of MRA treatment and controlled for the baseline AHI because they considered it a possible confounding factor in the response to treatment. In that study, the individuals who responded to the treatment exhibited an increased pharyngeal cross-sectional area and increased middle and lower airway space. In our study, the pretreatment AHI did not differ between the responders and non-responders, and these variables did not influence the model and showed no prediction influences. In contrast, the responders in our sample exhibited a reduction in the lower airway space.

Some authors reported ${ }^{13,14,17}$ that an MRA is more effective among individuals who exhibit the greatest number of respiratory events in the supine position, which was not found in our study. Because we did not include patients with severe OSAS or increased BMI, as the abovementioned studies did, other factors, such as the craniofacial conformation, may have exerted a greater influence on the results. Tsuiki et al. ${ }^{20}$ performed a retrospective study with patients with OSAS and an AHI of $>5$ who were already using CPAP with good adherence to the treatment. They showed that the individuals subjected to therapeutic CPAP pressures of $\leq 10.5 \mathrm{~cm} \mathrm{H}_{2} \mathrm{O}$ exhibited a satisfactory response to treatment with an MRA, which was different from the patients who required higher CPAP pressures. In the present study, we were not able to identify a possible cut-off point for CPAP pressure to predict therapeutic success.

Although Tsuiki et al. ${ }^{20}$ applied the same success criteria and the mean BMI of their sample was similar to ours, they assessed a Japanese population, which could mean that for their population the AHI were higher than in our study, which comprised a Brazilian population, which is known to be ethnically mixed. ${ }^{40}$ 
Bosoglu et al. ${ }^{41}$ asserted that race and ethnicity might be important determinants of body traits, the severity of OSAS, and effective CPAP pressures. Therefore, racial differences might account for the differences among the results observed.

The success of OSAS treatment with an MRA is greater among females compared to males. ${ }^{14}$ We have included only male subjects, since gender was identified as a possible confounding factor in the response to OSAS treatment with an MRA, as stated by other authors. ${ }^{39}$ This exclusion represents a limitation of the present study, as the results cannot be extended to women with OSAS.

Some studies indicated that younger patients exhibited a better response to an MRA. ${ }^{13,23,38}$ In our study, age was not an influential factor for treatment success. Our study is similar to the studies by Tsuiki et al. ${ }^{20}$ and Zeng et al., ${ }^{35}$ in which age did not correlate with the response to treatment, which is most likely because we established a rigorous criterion of success.

Although BMI and neck circumference are mentioned as possible predictors of the success of treatment with an MRA, ${ }^{38}$ in the present study, in which obese patients were excluded, BMI did not exert a significant influence on the success of treatment. This finding might be explained by the fact that our patients' BMIs were not too high or by the rigorous criterion of success that we applied. ${ }^{13,20,37}$.

No significant difference in the amount of mandibular advancement was found in our study between the responders and non-responders, which corroborates the results of Mostafiz et al. ${ }^{23}$ An increase in the elasticity of the tongue's soft tissue might limit the mechanical transmission of the mandibular advancement force to the base of the tongue..$^{39,42}$

In agreement with the findings by Liu et al. ${ }^{10}$ and Otsuka et al., ${ }^{39}$ we also found a reduction in the lower airway space in the responders. Individuals with a narrowing of the upper airways exhibited a greater tendency for collapse; thus, we may postulate that a volumetric increase in this area induced by an MRA, even in an upper location, might contribute to a reduction in the airway collapsibility, thereby promoting treatment success.
Regarding the increase in the upper pharyngeal space, we were not able to identify any study that employed cephalometry that correlated a specific variable with the success of an MRA for OSAS treatment. ${ }^{43,44}$ This result was corroborated by our ENT findings because the individuals without pharyngeal alterations, with a wider pharynx, also exhibited a better response to treatment. The remainder of the ENT parameters analyzed in the present study did not exhibit significant differences between the responders and non-responders.

Upon assessing linear measures in dental models, Mostafiz et al. ${ }^{23}$ did not find a significant difference between the responders and non-responders. Nevertheless, the authors observed a correlation between a larger upper intermolar width and a greater reduction of AHI when comparing the preand post-treatment periods. The same analysis was performed in the present study, and it was observed that the responders exhibited a greater lower intercanine width. Although the mechanisms by which an MRA is beneficial to OSAS are not clearly understood, increases in the upper airway dimensions and the craniofacial structure appear to play an important role. ${ }^{23,45}$

No variables that influenced the success of OSAS treatment with an MRA were identified based on a logistic regression analysis using the selected criterion of success as a dependent variable. In addition, no variables were identified by a linear regression analysis to be predictive of the percentage variation of the AHI before and after treatment with an MRA. We believe that this lack of predictive value of the variables might be due to the multifactorial nature of the response to OSAS treatment. Nevertheless, these findings represent an important contribution to the understanding of the mechanisms that underlie the efficacy of an MRA in OSAS treatment.

Some limitations of our study should be cited; the power analysis of our sample size and effect size was low, which may reflect a low number of patients included, and the inclusion criteria of only non-obese men could restrict our results for this population. 


\section{Conclusion}

Our results show that the treatment success in non-obese, non-severe OSAS patients with an MRA was greater among the patients with milder OSAS, an absence of pharyngeal alterations, increased upper pharyngeal space, reduced lower airway space, increased mandibular intercanine width, and a greater reduction of sleepiness following treatment.

\section{Acknowledgments}

\author{
AFIP, UNIFESP, FAPESP and CNPq.
}

\section{References}

1. AASM. Sleep-related breathing disorders in adults: recommendations for syndrome definition and measurement techniques in clinical research. The Report of an American Academy of Sleep Medicine Task Force. Sleep. 1999;22(5):667-89. https://doi.org/10.1093/sleep/22.5.667

2. Young T, Palta M, Dempsey J, Skatrud J, Weber S, Badr S. The occurrence of sleep-disordered breathing among middle-aged adults. N Engl J Med. 1993;328(17):1230-5. https://doi.org/10.1056/NEJM199304293281704

3. Peppard PE, Young T, Barnet JH, Palta M, Hagen EW, Hla KM. Increased prevalence of sleep-disordered breathing in adults. Am J Epidemiol. 2013;177(9):1006-14. https://doi.org/10.1093/aje/kws342

4. Tufik S, Santos-Silva R, Taddei JA, Bittencourt LR. Obstructive sleep apnea syndrome in the Sao Paulo Epidemiologic Sleep Study. Sleep Med. 2010;11(5):441-6. https://doi.org/10.1016/i.sleep.2009.10.005

5. Heinzer R, Vat S, Marques-Vidal P, Marti-Soler H, Andries $\mathrm{D}$, Tobback $\mathrm{N}$ et al. Prevalence of sleepdisordered breathing in the general population: the HypnoLaus study. Lancet Respir Med. 2015;3(4):310-8. https://doi.org/10.1016/S2213-2600(15)00043-0

6. Garvey JF, Pengo MF, Drakatos P, Kent BD. Epidemiological aspects of obstructive sleep apnea. J Thorac Dis. 2015;7(5):920-9. https://doi.org/10.3978/i.issn.2072-1439.2015.04.52

7. Ramar K, Dort LC, Katz SG, Lettieri CJ, Harrod CG, Thomas SM et al. Clinical practice guideline for the treatment of obstructive sleep apnea and snoring with oral appliance therapy: an update for 2015. J Clin Sleep Med. 2015;11(7):773-827.

8. Okuno K, Pliska BT, Hamoda M, Lowe AA, Almeida FR. Prediction of oral appliance treatment outcomes in obstructive sleep apnea: a systematic review. Sleep Med Rev. 2016;30:25-33. https://doi.org/10.1016/i.smrv.2015.11.007

9. Phillips CL, Grunstein RR, Darendeliler MA, Mihailidou AS, Srinivasan VK, Yee BJ et al. Health outcomes of continuous positive airway pressure versus oral appliance treatment for obstructive sleep apnea: a randomized controlled trial. Am J Respir Crit Care Med. 2013;187(8):879-87. https://doi.org/10.1164/rccm.201212-22230C

10. Liu Y, Park YC, Lowe AA, Fleetham JA. Supine cephalometric analyses of an adjustable oral appliance used in the treatment of obstructive sleep apnea. sleep breath. 2000;4(2):59-66. https://doi.org/10.1007/BF03045025

11. Menn SJ, Loube DI, Morgan TD, Mitler MM, Berger JS, Erman MK. The mandibular repositioning device: role in the treatment of obstructive sleep apnea. Sleep. 1996;19(10):794-800. https://doi.org/10.1093/sleep/19.10.794

12. Gotsopoulos H, Chen C, Qian J, Cistulli PA. Oral appliance therapy improves symptoms in obstructive sleep apnea: a randomized, controlled trial. Am J Respir Crit Care Med. 2002;166(5):743-8. https://doi.org/10.1164/rccm.200203-208OC

13. Liu Y, Lowe AA, Fleetham JA, Park YC. Cephalometric and physiologic predictors of the efficacy of an adjustable oral appliance for treating obstructive sleep apnea. Am J Orthod Dentofacial Orthop. 2001;120(6):639-47. https://doi.org/10.1067/mod.2001.118782

14. Marklund M, Stenlund H, Franklin KA. Mandibular advancement devices in 630 men and women with obstructive sleep apnea and snoring: tolerability and predictors of treatment success. Chest. 2004;125(4):1270-8. https://doi.org/10.1378/chest.125.4.1270

15. Ferguson KA, Cartwright R, Rogers R, Schmidt-Nowara W. Oral appliances for snoring and obstructive sleep apnea: a review. Sleep. 2006;29(2):244-62. https://doi.org/10.1093/sleep/29.2.244

16. Gotsopoulos H, Kelly JJ, Cistulli PA. Oral appliance therapy reduces blood pressure in obstructive sleep apnea: a randomized, controlled trial. Sleep. 2004;27(5):934-41. https://doi.org/10.1093/sleep/27.5.934

17. Yoshida K. Influence of sleep posture on response to oral appliance therapy for sleep apnea syndrome. Sleep. 2001;24(5):538-44. https://doi.org/10.1093/sleep/24.5.538

18. Almeida FR, Bittencourt LR, Almeida Cl, Tsuiki S, Lowe AA, Tufik $\mathrm{S}$. Effects of mandibular posture on obstructive sleep apnea severity and the temporomandibular joint in patients fitted with an oral appliance. Sleep. 2002;25(5):507-13. https://doi.org/10.1093/sleep/25.5.505 
19. Almeida FR, Parker JA, Hodges JS, Lowe AA, Ferguson KA. Effect of a titration polysomnogram on treatment success with a mandibular repositioning appliance. J Clin Sleep Med. 2009;5(3):198-204.

20. Tsuiki S, Kobayashi M, Namba K, Oka Y, Komada Y, Kagimura T et al. Optimal positive airway pressure predicts oral appliance response to sleep apnoea. Eur Respir J. 2010;35(5):1098-105. https://doi.org/10.1183/09031936.00121608

21. Hoekema A, Stegenga B, Bakker M, Brouwer WH, Bont LG, Wijkstra PJ et al. Simulated driving in obstructive sleep apnoea-hypopnoea; effects of oral appliances and continuous positive airway pressure. Sleep Breath. 2007;11(3):129-38. https://doi.org/10.1007/s11325-006-0093-7

22. Lee CH, Kim JW, Lee HJ, Seo BS, Yun PY, Kim DY et al. Determinants of treatment outcome after use of the mandibular advancement device in patients with obstructive sleep apnea. Arch Otolaryngol Head Neck Surg. 2010;136(7):677-81. https://doi.org/10.1001/archoto.2010.106

23. Mostafiz W, Dalci O, Sutherland K, Malhotra A, Srinivasan V, Darendeliler MA, et al. Influence of oral and craniofacial dimensions on mandibular advancement splint treatment outcome in patients with obstructive sleep apnea. Chest. 2011;139(6):1331-9. https://doi.org/10.1378/chest.10-2224

24. American Academy of Sleep Medicine - AASM. The International Classification of Sleep Disorders: diagnostic and coding manual. Westchester: American Academy of Sleep Medicine; 2005.

25. Rechtschaffen A, Kales A, editors. A manual of standardized terminology, techniques and scoring system for sleep stages of human subjects. Washington, DC: Public Health Services; 1968.

26. Iber CA, Chesson AL Jr, Quan SF. The AAM manual for the scoring of sleep and associated events: rules, terminology and technical specifications. Westchester: American Academy of Sleep Medicine; 2007.

27. Gottlieb DJ, Whitney CW, Bonekat WH, Iber C, James GD, Lebowitz M, et al. Relation of sleepiness to respiratory disturbance index: the Sleep Heart Health Study. Am J Respir Crit Care Med. 1999;159(2):502-7. https://doi.org/10.1164/ajrccm.159.2.9804051

28. Kushida CA, Chediak A, Berry RB, Brown LK, Gozal D, Iber $C$ et al. Clinical guidelines for the manual titration of positive airway pressure in patients with obstructive sleep apnea. J Clin Sleep Med. 2008;4(2):157-71.

29. Zonato Al, Bittencourt LR, Martinho FL, Júnior JF, Gregório LC, Tufik S. Association of systematic head and neck physical examination with severity of obstructive sleep apnea-hypopnea syndrome. Laryngoscope. 2003;113(6):973-80. https://doi.org/10.1097/00005537-200306000-00011

30. Johns MW. A new method for measuring daytime sleepiness: the Epworth sleepiness scale. Sleep. 1991;14(6):540-5. https://doi.org/10.1093/sleep/14.6.540

31. Ware JE Jr, Sherbourne CD. The MOS 36 -item shortform health survey (SF-36). I. Conceptual framework and item selection. Med Care. 1992;30(6):473-83. https://doi.org/10.1097/00005650-199206000-00002

32. McNair DM, Loor M, Droppleman LF. Manual for the profile of mood states. San Diego, Educational and Industrial Testing Service; 1971.

33. Dal-Fabbro C, Chaves Junior CM, Bittencourt LRA, Tufik S. Clinical and polysomnographic assessment of the BRD Appliance in the treatment of Obstructive Sleep Apnea Syndrome. Dental Press J Orthod. 2010;15(1):107-17. https://doi.org/10.1590/S2176-94512010000100013

34. Vanderveken OM, Devolder A, Marklund M, Boudewyns AN, Braem MJ, Okkerse W, et al. Comparison of a custom-made and a thermoplastic oral appliance for the treatment of mild sleep apnea. Am J Respir Crit Care Med. 2008;178(2):197-202. https://doi.org/10.1164/rccm.200701-114OC

35. Zeng B, Ng AT, Darendeliler MA, Petocz P, Cistulli PA. Use of flow-volume curves to predict oral appliance treatment outcome in obstructive sleep apnea. Am J Respir Crit Care Med. 2007;175(7):726-30. https://doi.org/10.1164/rccm.200608-12050C

36. Lim J, Lasserson TJ, Fleetham J, Wright J.

Oral appliances for obstructive sleep apnoea. Cochrane Database Syst Rev. 2006(1): CD004435. https://doi.org/10.1002/14651858.CD004435.pub2

37. Kushida CA, Morgenthaler TI, Littner MR, Alessi CA, Bailey D, Coleman J et al. Practice parameters for the treatment of snoring and Obstructive Sleep Apnea with oral appliances: an update for 2005. Sleep. 2006;29(2):240-3. https://doi.org/10.1093/sleep/29.2.240

38. Pliska BT, Almeida F. Effectiveness and outcome of oral appliance therapy. Dent Clin North Am. 2012;56(2):433-44. https://doi.org/10.1016/i.cden.2012.02.003

39. Otsuka R, Almeida FR, Lowe AA, Ryan F. A comparison of responders and nonresponders to oral appliance therapy for the treatment of obstructive sleep apnea. Am J Orthod Dentofacial Orthop. 2006;129(2):222-9. https://doi.org/10.1016/j.ajodo.2004.06.035

40. Miljeteig $\mathrm{H}$, Hoffstein V. Determinants of continuous positive airway pressure level for treatment of obstructive sleep apnea. Am Rev Respir Dis. 1993;147(6 Pt 1):1526-30. https://doi.org/10.1164/ajrccm/147.6_Pt_1.1526

41. Basoglu OK, Tasbakan MS. Determination of new prediction formula for nasal continuous positive airway pressure in Turkish patients with obstructive sleep apnea syndrome. Sleep Breath. 2012;16(4):1121-7. https://doi.org/10.1007/s11325-011-0612-z

42. Kato J, Isono S, Tanaka A, Watanabe T, Araki D, Tanzawa H et al. Dose-dependent effects of mandibular advancement on pharyngeal mechanics and nocturnal oxygenation in patients with sleep-disordered breathing. Chest. 2000;117(4):1065-72. https://doi.org/10.1378/chest.117.4.1065

43. Endo S, Mataki S, Kurosaki N. Cephalometric evaluation of craniofacial and upper airway structures in Japanese patients with obstructive sleep apnea. J Med Dent Sci. 2003;50(1):109-20. 
- Predictors of success for mandibular repositioning appliance in obstructive sleep apnea syndrome

44. Mayer G, Meier-Ewert K. Cephalometric predictors for orthopaedic mandibular advancement in obstructive sleep apnoea. Eur J Orthod. 1995;17(1):35-43.

https://doi.org/10.1093/ejo/17.1.35
45. Chan AS, Sutherland K, Schwab RJ, Zeng B, Petocz P, Lee RW, et al. The effect of mandibular advancement on upper airway structure in obstructive sleep apnoea. Thorax. 2010;65(8):726-32. https://doi.org/10.1136/thx.2009.131094 